\title{
EL PROYECTO DE OSKAR HANSEN PARA AUSCHWITZ Y LA MONUMENTALIZACIÓN DEL DEBATE SOBRE LA GUERRA
}

\author{
Mariano Molina Iniesta
}

\begin{abstract}
La propuesta de Oskar Hansen para el Monumento a las Víctimas del Fascismo en Auschwitz renunciaba a tener una forma inmutable, tanto por la interacción que reclamaba del visitante como por el efecto del paso del tiempo. De esta manera manifestaba su incapacidad para representar el horror provocado por la guerra, y menos aún para explicarlo. Adoptando la forma de un pedestal vacío, lo que verdaderamente pretendía monumentalizar era el debate que debía suscitarse en su superficie, de posiciones cambiantes e incluso contradictorias, pero necesario para evitar el olvido.
\end{abstract}

Palabras clave: $K$ monumento admonitorio, segunda posguerra, Auschwitz, Hansen

Keywords: Admonitory monument, Post-WWII, Auschwitz, Hansen

\begin{abstract}
"El monumento es, tanto para quienes lo edifican como para los que reciben sus mensajes, una defensa contra los traumatismos de la existencia, un dispositivo de seguridad. El monumento asegura, da confianza, tranquiliza al conjurar el ser del tiempo. Garante de los orígenes, el monumento calma la inquietud que genera la incertidumbre de los comienzos. Desafío a la entropía y a la acción disolvente que el tiempo ejerce sobre todas las cosas, naturales y artificiales, el monumento intenta apaciguar la angustia de la muerte y de la aniquilación"1.
\end{abstract}

Si damos por cierta esta afirmación, ¿cómo conmemorar aquello que precisamente amenaza nuestra existencia, los actos humanos que queremos borrar definitivamente, y precisamente por ello, no debemos olvidar jamás? Esa fue la paradójica situación a la que intentaron dar respuesta, de diferente manera, todos los países contendientes en la Segunda Guerra Mundial. Habiéndose desvelado finalmente a la opinión pública su auténtica naturaleza, el coste irreparable en vidas humanas, la ejecución de acciones de dudosa justificación por parte de todos los actores, ¿cómo dar testimonio para la posteridad de aquello que no debimos hacer, aquello que no queremos ser?

El planteamiento de este problema dio lugar, entre otras fórmulas, a la popularización del monumento admonitorio (en alemán mahnmal), que utilizaba frecuentemente restos físicos de la contienda como recordatorio de sus funestas consecuencias. En estos términos se convocó el concurso de 1957 para la creación de un Monumento Internacional a las Víctimas del Fascismo en el campo de Auschwitz-Birkenau. Mientras los edificios de Auschwitz I se habían convertido en museo en 1947 para dar testimonio fundamentalmente del martirio de la nación polaca por parte del Nazismo, el campo de Birkenau había sufrido un declive progresivo tras la guerra que amenazaba incluso con hacerlo desaparecer, por lo que se convirtió en emplazamiento del concurso cuyo carácter internacional trataba de evitar el tinte de propaganda comunista que ya empañaba al museo original. Así, se consiguió que Henry Moore presidiera el jurado, y que se presentaran en la primera fase 426 propuestas de muy diversa procedencia, de las que, según el relato de Agata Pietrasik ${ }^{2}$, se eligieron 8 para pasar a una segunda fase. De esas ocho finalmente tres fueron seleccionadas en 1958.

Es interesante comprobar la evolución paralela de estas tres propuestas, siguiendo la línea de quitar importancia al foco conmemorativo para no restar protagonismo a las ruinas. Y ello presumiblemente provocado por lo problemático del acontecimiento conmemorado y la experiencia directa de los restos del campo de exterminio. Así describía Giorgio Simoncini, integrante de uno de los equipos seleccionados, (Fig. 1) el impacto de su visita a Birkenau:

"La visita a Birkenau había revelado una realidad muy distinta a la imaginada estudiando la planimetría del campo. Sobre todo, nos dimos cuenta de la importancia que tenían las vallas en su percepción: la retícula transparente de cables metálicos que las componían estaba destinada no a separar, sino a poner visualmente en relación sus diferentes partes, mientras que su sucesión en perspectiva articulaba el espacio del campo, proporcionando la medida de su grandeza indefinida. Para conservar este tipo de percepción era necesario evitar cualquier elemento emergente del terreno, al contrario de lo que habíamos previsto en el proyecto precedente"3.
1. CHOAY, Françoise, Alegoría del Patrimonio, Gustavo Gili, Barcelona, 2007, pp. 12-13.

2. PIETRASIK, Agata, "Traversing Monumentality-Successive Designs for the Auschwitz Monument", Moore in Auschwitz. The Adam Mickiewicz Institute, Varsovia, 2010. 
Fig. 1. Propuestas de Simoncini, Valle, Vitale y Fazzini para las dos fases del concurso. En la segunda desaparece el elemento vertical dominando la composición. En: Giorgio Simoncini, La Memoria di Auschwitz, ilustraciones 2 y 19.

Fig. 2. Propuestas de Lafuente y los hermanos Cascella para las dos fases del concurso. Incluidas respectivamente en Giorgio Simoncini, op. cit, ilustración 6 y Julio Lafuente "Concurso para el monumento internacional de Auschwitz (Polonia) 1958”, Nueva Forma, 1973, n. 88, p. 10.
3. SIMONCINI, Giorgio, La Memoria di Auschwitz, Jaca Book Spa, Milán, 2012, p. 51.

4. Cita de Oskar Hansen incluida en PIETRASIK, Agata, op cit, no paginado.
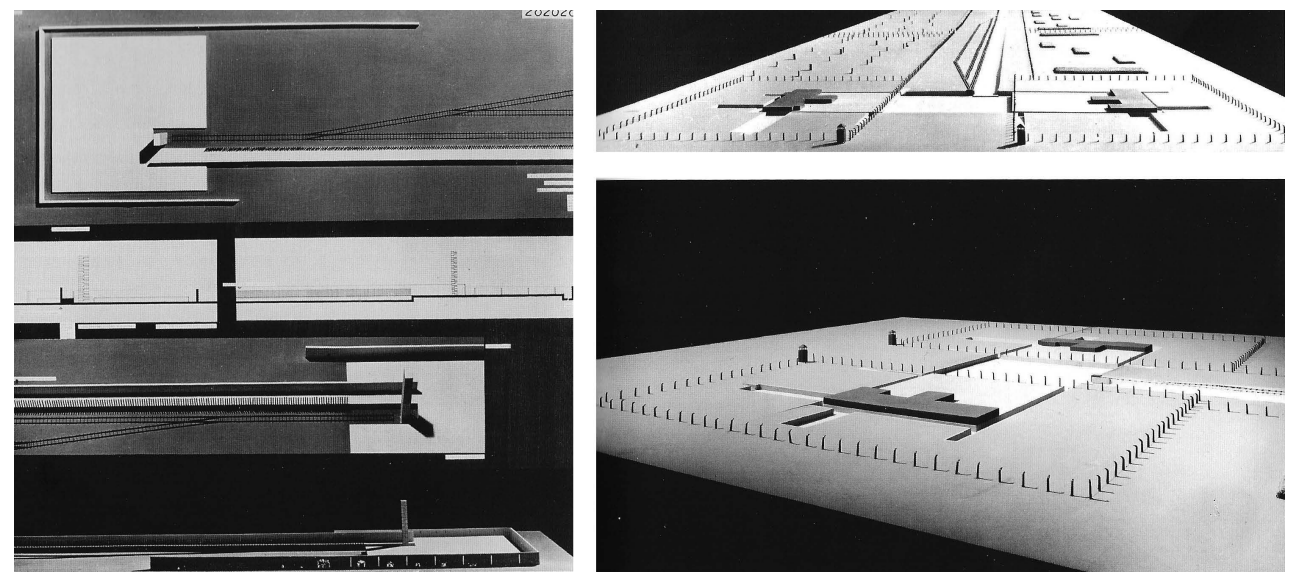

1
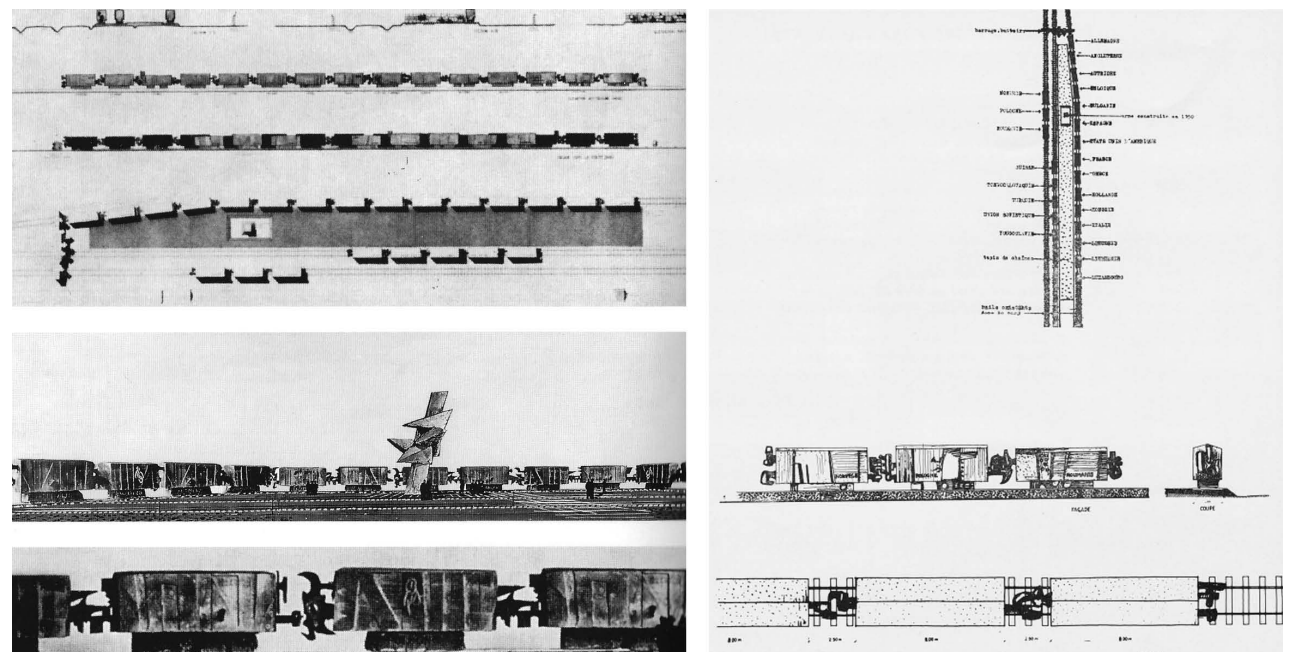

2

Por su parte, el equipo de Julio Lafuente y Pietro y Andrea Cascella, inspirado por las bases del concurso, planteaba la colocación de veintitrés vagones macizos sobre las vías que conducían a las cámaras de gas (Fig. 2), representando las nacionalidades de los internos del campo, conectados entre sí mediante broches inspirados en el alambre de espino de las vallas del campo, y bloqueados en su marcha por un muro de bloques de piedra. En su primera fase la propuesta no se resistía a incorporar un elemento escultórico central que jerarquizara la composición. Sin embargo, en la segunda fase ese elemento fue sustituido por una urna funeraria que ya se había colocado en la zona de los crematorios en 1950, y tenía mucho menor impacto visual.

Con todo, la evolución más radical fue la que sufrió la propuesta del equipo polaco liderado por el arquitecto Oskar Hansen, del que también formaban parte el escultor Jerzy Jarnuszkiewicz, el diseñador gráfico Julian Palka y el fotógrafo Edmund Kupiecki. En su primera versión (Fig. 3) planteaban la creación de una plataforma que, si bien renunciaba ya a la verticalidad, se organizaba en torno a un vacío deprimido en el terreno que contendría una urna con cenizas de internos de todos los campos de concentración de Europa. A pesar de la cálida acogida por parte del jurado, el equipo no estaba satisfecho con su propuesta:

"Cuando pasamos a la segunda fase del concurso, comenzamos a tener dudas sobre las bondades de nuestro
diseño. La inmovilidad cristiana o judía de nuestra plataforma, o incluso su pasividad, su naturaleza anacrónica,
le impedía convertirse en un símbolo contemporáneo, universal. El proyecto nos resultaba cada vez más ajeno"4

La novedad de su segunda propuesta se basó entonces no ya en reducir, sino en eliminar por completo el espacio conmemorativo al uso, tanto por la ausencia de un hito que lo marcara, como por la disposición y dimensiones que adquirió la huella de su proyecto (Fig. 4). 
Su 'Monumento-Camino' era una plataforma elevada que recorría diagonalmente el campo de exterminio, conduciendo al visitante a través de los barracones hasta llegar a los crematorios. Se evitaba así la teatralidad de la secuencia de acceso tradicional al campo en tren, poniendo el énfasis en las deplorables condiciones del día a día de los internos. Pero al mismo tiempo se evitaba el contacto directo con las ruinas, de manera que el visitante tuviera conciencia de su propia subjetividad a la hora de percibir y evaluar su experiencia. Eventualmente se permitiría que las ruinas del campo acabaran desapareciendo con el paso del tiempo y la plataforma quedara rodeada simplemente de naturaleza.

\section{La memoria del proyecto decía:}

"La puerta que antes servía de entrada se ha cerrado - un cierre simbólico- siendo el único recuerdo de ella la perspectiva de los raíles, la entrada abierta se alcanza a pie. Desde aquí, un 'camino' de granito de 60 metros de ancho y un kilómetro de largo corta diagonalmente el campo completo; una sección transversal, como si dijéramos, en la que las pruebas de lo que sucedió en el campo-fragmentos de barracones, letrinas, chimeneas- permanecen enmarcados en piedra. La calle sigue atravesando la valla, cruzando los raíles en canales tallados. De nuevo la puerta; esta vez en la distancia. A continuación, los andenes y los crematorios y paralela la pequeña escalera hacia el lugar donde estaban las cámaras de gas, un símbolo que determina la dirección del camino. Finalmente, la amplia escalera, saliendo del campo hacia la vida. Merodeando en torno a los restos caídos muchos querrán dejar flores junto a los símbolos inscritos por la gente por todas partes"5.

El carácter excesivamente abstracto y centrado más en la respuesta del visitante que en el homenaje a las víctimas despertó las suspicacias de los supervivientes del campo, que acabaron por decantar la decisión del jurado. A pesar de que Moore consideraba "excepcionalmente brillante" la propuesta de Hansen, al anunciar el fallo del concurso en París en 1958, no proclamó vencedora a ninguna de las propuestas finalistas:

"La elección de un monumento para conmemorar Auschwitz no ha sido tarea fácil. Esencialmente, lo que se ha intentado es la creación -o en el caso del jurado la elección- de un monumento al crimen y la fealdad, al crimen y el horror. El crimen era de tales proporciones que cualquier obra de arte debe ser de la escala adecuada. Pero, aparte de esto, ¿es posible en realidad crear una obra de arte que exprese las emociones que Auschwitz genera?

Tengo la convicción de que un escultor genial - un nuevo Miguel Ángel o un nuevo Rodin- podría haberlo conseguido. Las dudas sobre el diseño que surgían entre las maquetas presentadas eran enormes. Y ninguna lo consiguió. Tampoco había un proyecto puramente arquitectónico completamente satisfactorio.

Quedaron al final tres proyectos que se consideraron buenos, pero ninguno de ellos completamente adecuado. El jurado consideró que su tarea fundamental no era otorgar un premio, decidir cuál de los tres era mejor, sino asegurarse de que se construyera el mejor monumento posible en Auschwitz.

Con esta visión se tomó una decisión unánime: los tres mejores equipos fueron seleccionados para presentar, si fuera posible en colaboración, pero si fuera necesario individualmente, un proyecto o proyectos nuevos. Se dará un fallo definitivo en 1959. El jurado se reunirá de nuevo para decidir si alguno de estos proyectos merece su aprobación, y si es así, cuál de ellos"6.

Los tres equipos seleccionados accedieron a trabajar en una propuesta común que incluyera lo mejor de cada una de ellas. Tras ser revisada y aprobada por el jurado, en 1961 se les informó de que ya no era viable: costaría demasiado y desplazaría muchos edificios del campo recién reconstruidos. Tras dos años más de discusión, representantes de los tres equipos formaron un único grupo y presentaron una versión drásticamente reducida en escala limitada al área inmediata de los crematorios (Fig. 5), en la que la idea de Hansen era ya irreconocible. La comisión técnica y el gobierno la aprobaron, y la construcción comenzó dos años más tarde. Con todo, el monumento aún sufriría modificaciones durante el proceso de ejecución.

El proyecto de Hansen, al renunciar al elemento focal y permitir que continuara el deterioro de los restos del campo (a lo que se añadía la posibilidad de que el visitante dejara algún rastro de su paso), no pretendía tener una presencia inmutable y reflejaba la contingencia de cualquier significado o recuerdo. Al mismo tiempo obligaba a que el espectador soportara el peso de la memoria, consciente de que las ruinas estaban llamadas a desaparecer. El campo original, tan frágil en su construcción que requería una reconstrucción constante para permanecer en estado de ruina, estaba inevitablemente abocado a desvanecerse. Y cualquier proceso de consolidación (y no digamos de reconstrucción), por muy objetivo que fuera, suponía una transformación del original que podía utilizarse ideológicamente (y de hecho lo fue) en un sentido y otro.
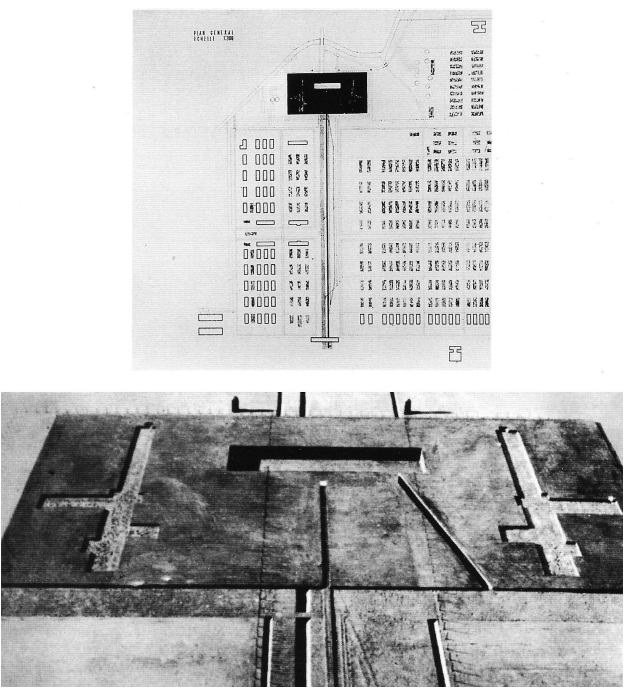

Fig. 3. Propuesta de Hansen, Jarnuszkiewicz, Palka y Kupiecki para la primera fase del concurso. En Giorgio Simoncini, op. cit, ilustración 5 .
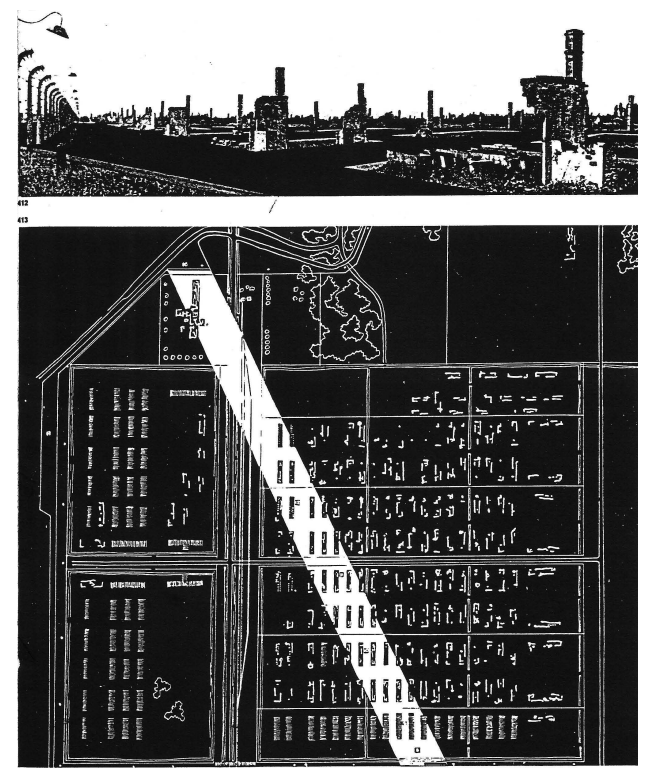

Fig. 4. Vista del campo de Birkenau y propuesta de Oskar Hansen para la segunda fase del concurso. En: Oscar Newman (ed), CIAM'59 in Otterlo, p. 192

5. HANSEN, Oskar et al. "Design for the Auschwitz Monument”, En Oscar Newman (ed), CIAM'59 in Otterlo, Universe Books, Nueva York, 1961, p. 193.

6. YOUNG, James, The Texture of Memory. Holocaust, Memorials and Meaning, Yale University Press, New Haven, 1993, p. 135. 
Fig. 5. Propuesta conjunta de 1959 de los tres equipos seleccionados en el concurso para el Monumento de Auschwitz. En: Giorgio Simoncini, op. cit, ilustración 34.
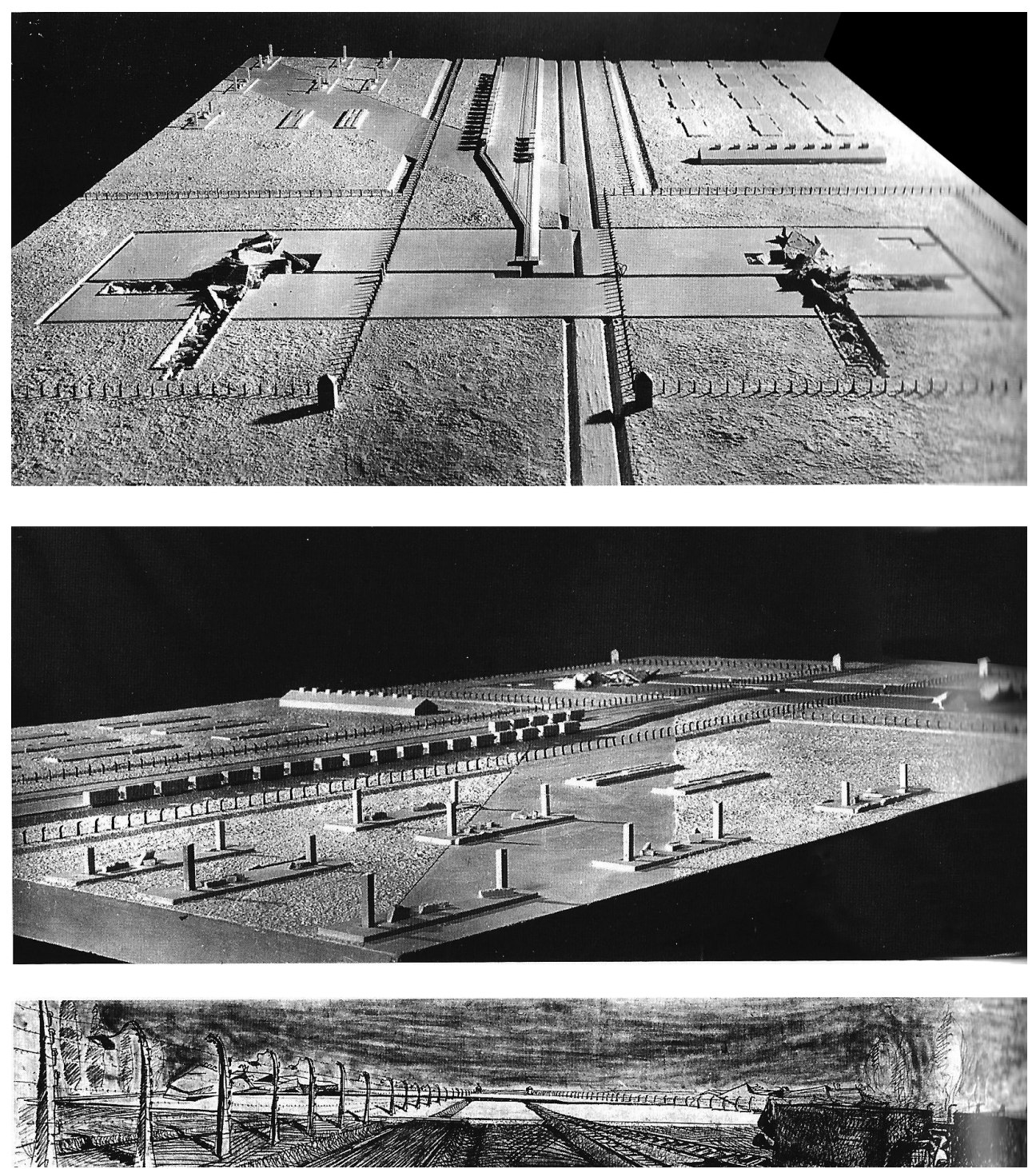

Además, fuera Hansen consciente o no, la incapacidad que tienen las ruinas de conservar un mensaje imperecedero sobre la crueldad de la guerra ya se había demostrado en el caso de Oradour-sur-Glane (Fig. 6), un pueblo francés arrasado por el ejército alemán en 1944 sin motivo aparente, que se convirtió en símbolo del sufrimiento de una población inocente, y como tal se trató de preservar exactamente como quedó tras el ataque, incluyendo tanto las ruinas de los edificios como los objetos de la vida cotidiana.

Sin embargo, limitados en su capacidad de intervención para no restar autenticidad a las ruinas de Oradour, los arquitectos conservadores se resignaron a que éstas adquirieran con el tiempo un aire nostálgico y romántico que terminó por socavar la intención primera del monumento, la representación del horror de la guerra de forma emocionalmente efectiva.

7. FARMER, Sarah. Martyred Village. Commemorating the 1944 Massacre at Oradour-sur-Glane. University of California Press, Berkeley, 1999, pp. 200-201.
"La restauración continua despierta el dilema que ha perseguido a las ruinas de Oradour desde el comienzo; si las ruinas se consideran verdad histórica por sí mismas, cualquier intento de conservación introduce elementos artificiales que amenazan con falsificar la historia [] La conservación por tanto amenaza con socavar la premisa básica para conservar las ruinas - puesto que era su carácter auténtico lo que se suponía que les daba significado. Si las ruinas cambian, se hacen irreconocibles, o desaparecen, de acuerdo a la lógica del monumento, también puede hacerlo la memoria"7.

Peor aún, el propio Nazismo, en boca de su arquitecto Albert Speer, se proponía sacar partido del aire romántico que el paso del tiempo daría a lo construido. Speer pensaba que ese lento declive ayudaría a la mitificación de los monumentos del Reich, y generaría una respuesta emotiva de admiración y simpatía. La "teoría del valor como ruina" fue el concep- 
to en el que Speer plasmó esta idea ${ }^{8}$. Aceptando por tanto la imposibilidad de controlar el efecto del tiempo para unos fines concretos, la propuesta de Hansen se resistía a ser diseñada en términos visuales, y por supuesto a ser representada gráficamente. La interacción que reclamaba del usuario, así como el proceso natural de envejecimiento, hacían que su apariencia fuera el resultado de procesos aleatorios e impredecibles, dando lugar al carácter dual de lo irrepresentable de su propuesta (irrepresentable en términos de proyecto artístico y como imagen verídica de la guerra). Hansen no sólo renunció al control formal en el proyecto de Auschwitz, sino que convirtió la participación activa del ciudadano en guía de toda su obra arquitectónica, por medio de lo que definía como 'Forma Abierta', aunque obviamente ésta resultaba especialmente provocativa en el ámbito conmemorativo:

"La diagonal se dispuso con el objetivo de mostrar el mecanismo del campo pero se pretendía que significara algo más - la superación de la forma, según la idea de la Forma Abierta, la superación que crea las condiciones para la recepción y la participación, que visualiza el subtexto de interacciones espaciales. El camino es un lugar para los gestos espontáneos. Si alguien desea dejar una nota con un nombre, o la figura de un ángel, puede hacerlo junto al camino"”.

Su absoluta excepcionalidad se anticipaba a diversas estrategias que, como mínimo, tardarían una década en materializarse. Por ejemplo, se ha señalado repetidamente que el proyecto de Auschwitz preludiaba la postura posmoderna de privilegiar al espectador por encima del objeto y la noción del campo expandido de la escultura de la que hablaría Rosalind Krauss ${ }^{10}$ mucho más tarde. Con la nueva forma que planteaba de afrontar el recuerdo, se convirtió también en el precursor de toda una serie de anti-monumentos, diseñados por una generación de artistas, fundamentalmente alemanes, posterior a la que vivió la guerra. Liberados de la vergüenza y la amnesia de sus predecesores, pero aún enfrentados a los restos de los campos de concentración que habían adquirido un estatus sagrado, estos artistas trataron de superar la incapacidad para el duelo de sus padres:

"[L]a lógica didáctica de los monumentos, su rigidez demagógica, recordaban demasiado fielmente los rasgos que asociaban al propio fascismo. Su monumento contra el fascismo, por tanto, se convertiría en un monumento contra sí mismo: contra la función didáctica tradicional de los monumentos, contra su tendencia a desplazar el pasado que debería mostrarnos -y finalmente, contra la propensión autoritaria de todo arte que reduce a los espectadores a un papel pasivo [ ] [E]l anti-monumento desprecia muchas de las convenciones más queridas del monumento: su objetivo no es consolar sino provocar; no permanecer fijo sino cambiar; no ser eterno sino desaparecer; no ser ignorado por los viandantes sino reclamar interacción; no permanecer puro sino invitar a su propia violación y desacralización; no aceptar gentilmente la carga de la memoria sino devolverla a los pies de la ciudad [ ] Al negar su forma, sin embargo, el anti-monumento no necesita negar la memoria. Y al desafiar sus razones de ser, tampoco desafía la propia demanda de memoria. Más bien sólo niega la ilusión de permanencia tradicionalmente fomentada por el monumento. Porque al llamar la atención sobre su presencia fugaz, el anti-monumento se burla de la certidumbre sobre la historia tradicional del monumento" 11 .

Pero sobre todo, al renunciar a 'hablar', es decir, a presentar los restos del campo dentro de un relato concreto, lo que parece intuirse es que la propuesta de Hansen habría conservado su pertinencia a lo largo del tiempo, a pesar de los cambios de posición que se han sucedido tras la guerra hacia el tratamiento que debe hacerse de los restos del Nazismo. Así, inmediatamente después de ella se inició un proceso de 'De-nazificación', consistente habitualmente en la retirada de los símbolos más evidentes y la reutilización de estos restos con fines prácticos. Esta posición se definía como un enfoque 'no-ideológico', por cuanto que apelaba simplemente a la necesidad de aprovechar los escasos recursos materiales de los que se disponía.

"Los edificios nazis [ ] se mantuvieron, de hecho, intactos. Parece que se demandó muy poco su destrucción en la década de posguerra [ ] En relatos posteriores, se daban a menudo razones prácticas [ ] En una ciudad reducida a escombros por el bombardeo aliado, cualquier edificio en pie debería, y era puesto en uso"12.

Esta estrategia era mucho más popular en Alemania Federal, y en su pragmatismo parecía alinearse con la fórmula del living memorial, dominante en Estados Unidos: ganar la guerra permitió seguir disfrutando de un modo de vida que, en términos arquitectónicos, quedaba plasmado en determinados equipamientos que debían convertirse en los nuevos monumentos; unos monumentos destinados a servir a los vivos, y no tanto a honrar a los muertos. Lo que sucedía entonces era que, tanto los living memorial americanos como los edificios del Nazismo reutilizados, imbuidos en la vida cotidiana, perdían fácilmente cualquier rastro de valor conmemorativo o simbólico, y la cara más amarga de la guerra se mantenía convenientemente oculta.

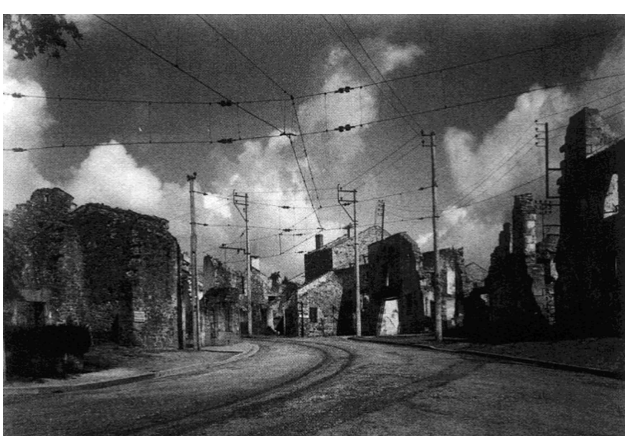

Fig. 6. Las ruinas de Oradour como monumento histórico. En: Farmer, S., Martyred Village, p. 204.
8. SPEER, Albert, Memorias, Acantilado, Barcelona, 2001, p. 104. 9. Cita de Oskar Hansen incluida en BIELECKI, Czeslaw: "Pragmatyzm utopii: Hansen”. Architektura, vol. 31, n. 3, p. 14.

10. KRAUSS, Rosalind, "La escultura en el campo expandido", en Hal Foster (ed), La Posmodernidad,, Editorial Kairós, Barcelona, 2002, pp. 59-74.

11. YOUNG, James, op. cit., pp. 28-48.

12. MACDONALD, Sharon, "Words in Stone?: Agency and Identity in a Nazi Landscape", Journal of Material Culture, vol. 11, n. $1 / 2$, p. 115 . 


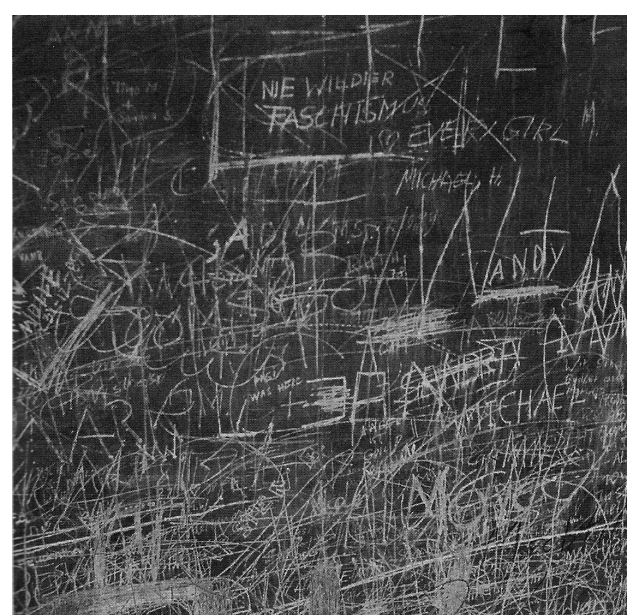

Fig. 7. Detalle del Monumento contra el Fascismo de Jochen y Esther Gerz, donde se aprecia la interacción con el visitante. En: James Young, The Texture of Memory, p. 35.
En el caso concreto de Alemania, esa tendencia al olvido propiciada por el uso cotidiano de los edificios fue crecientemente denunciada como 'incapacidad de aceptar el pasado' o 'amnesia estratégica'. Y a medida que aumentaron estas críticas se fue reconsiderando el tratamiento que debía darse al legado arquitectónico del Nazismo, llegándose en la década de 1970 a otorgárseles protección patrimonial e incluso a restaurar elementos que habían sido previamente demolidos (de forma relevante la Sala Dorada del Campo de Zeppelines de Núremberg

\begin{abstract}
"La restauración prosiguió con poca oposición pública. Una razón de peso parece ser que se realizaba no para restaurar el patrimonio nazi sino dotar de un espacio en el que la 'historia reciente' de la ciudad pueda tratarse y 'superarse' [ ] Ello significó un cambio relevante en la forma de pensar sobre el pasado [ ] En lugar de tratar de 'borrar' la 'mancha' del pasado, enfoque predominante a comienzos de la década de 1970, al llegar a los 80, se había popularizado un discurso identitario cargado de psicoanálisis que invitaba a 'afrontar' y 'elaborar' el pasado"'13.
\end{abstract}

En ese contexto de revisión del pasado, durante la década de 1980, floreció el anti-monumento (Gegendenkmal) al que se aludía antes, con ejemplos que replicaban de forma directa las estrategias de Hansen en Auschwitz: particularmente, el Monumento contra el Fascismo diseñado en Hamburgo por Jochen y Esther Gerz (Fig. 7) consistía en un monolito de aluminio recubierto de grafito, pensado para que el visitante pudiera grabar fácilmente en sus paredes cualquier mensaje. A medida que estas intervenciones ocuparan todo el espacio disponible, el monolito se iría hundiendo en el terreno para proporcionar nueva superficie para la interacción, hasta acabar desapareciendo por completo. Como en Auschwitz, se pretendía generar una respuesta activa del espectador y aceptar la caducidad del monumento. Pero curiosamente, incluso esta actitud crítica hacia su pasado ha acabado por generar suspicacia, en la medida en que su proliferación parece haber otorgado a los alemanes un halo de superioridad moral.

"Si el 'nacionalismo negativo' se ha convertido en el hito de la identidad alemana contemporánea- un ter-
mino con connotaciones de culpabilidad, y paradójicamente auto-indulgente, incluso orgulloso, compro-
metido con la búsqueda de todo lo relacionado con la historia alemana y el mal alemán- entonces el Monu-
mento al Holocausto debe percibirse verdaderamente como un testimonio grandilocuente del estado actual
de la conciencia colectiva [ ] Por todo lo que tiene este mensaje de negativo, ofrece un rayo de esperanza:
este estado de no redención permanente puede aliviarse, si no ennoblecerse éticamente, mediante el com-
promiso con la memoria. Quizá esta no-redención ilustrada, paradójicamente, es incluso una redención"14.

Como reacción a ese exceso, y aceptando que esa fase del pasado ya se ha superado, hoy día se vuelven a recuperar edificios del Nazismo para usos prácticos, con ejemplos tan aparentemente irreverentes como la conversión de la estación transformadora del complejo de Núremberg en un restaurante de comida rápida, que Martin Beckstein considera "testimonio de la autoconfianza recuperada de la nación alemana"15. Queda claro entonces que las intervenciones sobre el patrimonio del Nazismo varían de forma pendular, y que, como afirma Young, "en lugar de una figura fija para el recuerdo, es el propio debate - permanentemente no resuelto en medio de unas circunstancias permanentemente cambiantes- el que debe sacralizarse"16. Y Hansen, al dejar vacía su plataforma en Auschwitz hace precisamente eso, crear el pedestal sobre el que el visitante, en tanto que participante activo en ese debate, se convierte en el auténtico monumento.
13. MACDONALD, Sharon, op cit., p. 119

14. NIVEN, Bill, "From Countermonument to Combimer rial: Developments in German Memorialization”, Journal of War \& Culture Studies, vol. 6, n. 1, p. 83.

15. BECKSTEIN, Martin, "Nation Building in Contemporary Germany, The strange transformation of Hitler's "word made of stone"", Nations and Nationalism, vol. 19, n. 4, pp. 761-780. 16. YOUNG, James, "The Counter-Monument: Memory against Itself in Germany Today", Critical Inquiry, vol. 18, n. 2, p. 270
Mariano Molina Iniesta. Arquitecto desde 1997 por la Universidad Politécnica de Madrid, especialidad en Edificación. Primer Premio Nacional de Terminación de Estudios Universitarios de Arquitectura. Colaborador en el estudio de Rafael Moneo entre 1997 y 2000. Becario de La Caixa para realización de estudios de postgrado en EEUU. Master in Architecture with Distinction 2002, Universidad de Harvard. Premio Kevin Kieran 2002. Profesor colaborador desde 2002 en el área de Estructuras de la Escuela Politécnica Superior de la Universidad CEU San Pablo de Madrid. Profesor desde 2004 en el Master de Estructuras Varias de la Escuela de la Edificación y la Universidad Politécnica de Madrid. Doctor arquitecto por la Universidad Politécnica de Madrid desde 2015, por la tesis titulada "La idea de Monumentalidad en la Segunda Posguerra: Debates y Propuestas". La investigación desarrollada en este campo incluye los siguientes artículos: "Kenzo Tange. Monumentos de guerra y paz". Constelaciones, n. 1, pp. 129-142. Madrid, Mayo de 2013; "Conmemorar o construir la historia: Cambridge Honor Roll vs St Louis Gateway Arch". Constelaciones, n. 2, pp. 61-74. Madrid, Mayo de 2014; "Mahnmale y living memorials en la reconstrucción francesa de posguerra". ZARCH. Journal of interdisciplinary studies in Architecture and Urbanism, n. 6, pp. 44-55. Zaragoza, 2016; "La catenaria ponderada de Saint Louis: Ley universal y genio individual en la evolución del Movimiento Moderno de posguerra". RITA. Revista Indexada de Textos Académicos, n. 6, pp. 110-115. Octubre 2016; "Memorias en conflicto: el caso de Coventry". ESTOA. Revista de la Facultad de Arquitectura y Urbanismo de la Universidad de Cuenca, $\mathrm{n}$. 10, vol. 6, pp. 21-33, enero-junio 2017. 


\section{PETICIÓN DE COMUNICACIONES}

\section{La tecnología en la arquitectura moderna (1925-1975): mito y realidad}

\section{La casa es una máquina para vivir}

Son muchos los relatos de la génesis del Movimiento Moderno que establecen sus orígenes en la acción tecnológica y funcional de los ingenieros, estéticamente despreocupada; la tecnología aparece, a menudo, como argumento causal de las novedades en el diseño de sus espacios construidos. Esto ha solido llevar a ver el progreso estético de la modernidad como algo encontrado y subordinado, forzado por los nuevos materiales, a modo de resultado inevitable.

Quizá valga la viceversa y quepa pensar que esos avances tecnológicos son justo una respuesta a las nuevas necesidades espaciales y funcionales. En todo caso, ellos han acompañado a todo lo largo del siglo XX a la caracterización estética, espacial y hasta funcional de la arquitectura.

Su evolución se sabe indisociable de las posibilidades deducibles de la aparición del hormigón armado y el pretensado, el acero y el aluminio, el vidrio laminado, la luz eléctrica, los elevadores, la climatización...; quizá la arquitectura moderna no se entienda, incluso, sino a la luz de las expectativas utópicas ligadas a ellas.

Sea cual sea el papel que debamos reconocer a la industria en su definición, en fin, la arquitectura moderna no puede entenderse sin esos avances. Los espectaculares desarrollos de la arquitectura en materia de expresividad y lenguaje dependen de ellos, por mucho que no hayan alcanzado los fantasiosos resultados soñados por algunos en los felices años veinte.

La caducidad de las soluciones técnicas ha lastrado algunos de los logros plásticos de la arquitectura moderna. No pocos de sus frutos más vistosos se ven dañados en su reconocimiento y estima por los defectos derivados del recurso a avances audaces o poco maduros en su momento. Sin embargo, sin duda esto es más algo a comprender que algo a magnificar como parte del 'debe' de la arquitectura moderna.

La consideración del papel jugado por la tecnología, entendida en sentido amplio, será el objeto de estudio del Congreso, que tendrá tres secciones:

\section{COMITÉ CIENTÍFICO / \\ SCIENTIFIC COMITEE \\ Ana Tostoes \\ Joaquin Medina Warmburg \\ Juan M. Otxotorena \\ Antonio Pizza \\ José Manuel Pozo \\ José Ángel Medina \\ Wilfried Wang \\ SECRETARIA / SECRETARY \\ Pablo Arza \\ (congresoetsaun@unav.es)}

INSCRIPCIÓN / REGISTRATION

La cuota de inscripción será de 180

euros si se formaliza antes del dia 23

de marzo de 2018 , y de 250 euros si se

hiciera después. El pago deberá realizarse

a través de la página web del congreso

http://www.unav.es/congreso/historia-

arquitectura/inscripcion.

The registration fee is 180 euros if paid before March 23rd 2018 and 250 euros after this date. Payment of the fees should be made through the web http://www. unav.es/congreso/historia-arquitectura/ inscripcion.

\section{CALENDARIO PRELIMINAR /}

PRELIMINARY CALENDAR

10 Junio 2017 Límite de recepción de propuestas (máx. 400 palabras). Las

propuestas (español o inglés) se enviarán a congresoetsaun@unav.es cumplimentando la plantilla disponible en la web.

10 Julio 2017 Comunicación a los autores de las propuestas seleccionadas.

15 Noviembre 2017 Fecha limite de entrega (máx. 4.000 palabras). Las comunicaciones (español o inglés) se enviarán a congresoetsaun@unav.es. June 10th 2017 Deadline for abstracts reception (máx. 400 words). Abstracts, (Spanish or English) should be sent to congresoetsaun@unav.es using the template available on the web. July 10th 2017 Deadline for papers approval. November 15th 2017 Deadline for papers reception (máx. 4.000 words). Papers (Spanish or English) should be sent to congresoetsaun@unav.es.
1. La tecnología al servicio de la tectónica. Logros y tentativas

2. La estética tecnológica

3. El mito de la técnica, ilusión y realidades

\section{CALL FOR PAPERS \\ Constructing Modern Architecture: Myth and Reality (1925-1975)}

\section{A house is a machine for living in}

Many accounts of the genesis of Modernism identify its origins with the technological and functional, i.e., aesthetically unconcerned, approach adopted by engineers. Technology is often cited as the source of the innovative design that characterises the movement's built spaces. The result has been a tendency to deem that Modernism's aesthetic progress was inherited, subordinate, an inevitable outcome of the advent of new materials.

Perhaps the reverse is true. Perhaps technology advanced as a response to new spatial and functional demands. Whichever the case, throughout the twentieth century such progress was attendant upon architecture's aesthetic and spatial, even its functional, characterisation.

The movement's evolution is generally accepted to be indivisible from the potential inherent in reinforced and prestressed concrete, steel and aluminium, laminated glass, electric light... lifts, air conditioning: modern architecture may not even be understandable if not in the light of the resultant utopian expectations.

Whatever the role eventually acknowledged to industry in its definition, modern architecture is incomprehensible without such advances. The spectacular development of architectural expression and language depended on technology, even if the fanciful results envisioned by some in the nineteen twenties failed to materialise.

By the same token, the extinction of technical solutions has detracted from some of modern architecture's plastic achievements. The esteem and appreciation owed more than a few of its most handsome finds have been jeopardised by flaws attributable to the deployment of what at the time was daring or immature technology. That, however, is more something to be understood than magnified on the 'debit' side of the modern architectural balance sheet.

Consideration of the role played by technology in the broadest sense of the word will be the theme addressed by the three sections of the Congress:
1. Technology at the service of tectonics. Achievements and endeavours
2. The aesthetics of technology
3. The technical myth: illusion and reality 